\title{
Surface, Thermal and Antimicrobial Release Properties of Plasma-Treated Zein Films
}

S.K. Pankaj ${ }^{1}$, C. Bueno-Ferrer ${ }^{1}$, N.N. Misra ${ }^{1}$, L. O’Neill $^{2}$, A. Jiménez ${ }^{3}$, P. Bourke ${ }^{1}$ and P.J. Cullen*,1

${ }^{1}$ BioPlasma Research group, School of Food Science and Environmental Health, Dublin Institute of Technology, Cathal Brugha Street, Dublin 1, Ireland

${ }^{2}$ FOCAS Research Institute/School of Physics, Dublin Institute of Technology, Kevin Street, Dublin 8, Ireland

${ }^{3}$ University of Alicante, Analytical Chemistry, Nutrition and Food Sciences Department, PO Box 99, 03080 San Vicente del Raspeig, Alicante, Spain

*Corresponding author: pjcullen@dit.ie 


\section{ABSTRACT:}

The effects of dielectric barrier discharge plasma treatment on zein film containing thymol as an active ingredient were evaluated. The plasma discharge was optically characterized to identify the reactive species. A significant increase in the film roughness $(p<0.05)$ was observed due to the etching effect of DBD plasma, which was correlated with the increase in the diffusion rate of thymol in the food simulant. The diffusion of thymol from the zein film was measured in aqueous solution. The kinetics of thymol release followed the Fick's law of diffusion as shown by the high correlation coefficients between experimental and theoretical data. No significant change $(p>0.05)$ was observed for the thermal properties of the antimicrobial films after DBD plasma treatment.

KEYWORDS: Non-thermal plasma, DBD plasma, antimicrobial packaging, zein, thymol, release kinetics 


\section{INTRODUCTION}

The health concerns for consumers and environmental problems from packaging waste have driven a lot of research in the last few decades to develop new environmentally friendly materials. Although the packaging industry is still dominated by petroleum-derived polymers, the market for bioplastics is growing at a rate of more than 20 percent per year [1]. It seems challenging to completely replace conventional polymers with eco-friendly films, but at least for specific applications like food packaging, the use of bioplastics is considered highly promising [2].

Zein, the major storage corn protein having a high content of hydrophobic amino acids, has been extensively used to produce biodegradable films [3]. Zein films are glossy, hydrophobic, greaseproof and resistant to microbial attack, ensuring their suitability as coatings and packaging films for food products $[3,4]$. An important factor that could promote zein as industrial polymeric material for food packaging applications is the incorporation of antimicrobial compounds into its matrix [5]. Antimicrobial food packaging is a form of active packaging, which acts to reduce, inhibit or retard the growth of microorganisms that may be present in the packed food or packaging material itself [6]. The use of antimicrobial packaging material offers promise for enhancing the efficacy of existing antimicrobial agents and minimizing environmental problems by reducing their residual toxicity, increasing efficiency and selectivity, and prolonging their lifetime [7].

The uses of plant extracts, like essential oils, as antimicrobial additives are perceived safe [8]. Essential oils are aromatic oily liquids obtained from plant material like flowers, buds, seeds, leaves, twigs, bark, herbs, wood, fruits and roots [9]. Essential oils are very complex 
natural mixtures containing hydrocarbons (mainly terpenoids) and oxygenated compounds (alcohols, esters, ethers, aldehydes, ketones, lactones, phenols and phenol ethers) [10]. Essential oils such as eugenol and thymol, and plants extracts and spices like rosemary or cinnamon are the most commonly used natural active compounds for development of effective packaging systems [11]. Thymol is most abundantly found in thyme (Thymus vulgaris) (10-64\%) and oregano (Origanum vulgare) (traces-64\%), formed via $p$-cymene from $\mathrm{p}$-terpinene $[9,12,13]$. The study conducted by Dorman and Deans [14] on the effect of six plant volatile oils against twenty-five bacterial strains concluded that thymol has a very wide spectrum of antibacterial activity.

Non-thermal plasma is a novel technology which has gained significant attention for the decontamination of food products $[15,16]$. Dielectric barrier discharge (DBD) is one of the common methods to generate non-thermal plasma. In DBD, plasma is generated between two plane-parallel metal electrodes among which at least one of them is covered by a dielectric layer. The dielectric layer plays an important role in limiting the discharge current to avoid the arc transition and randomly distribute streamers on the electrode surface, resulting in a homogeneous treatment [17]. The DBD plasma is well known for the modification of both the surface and bulk properties of polymers [18]. The effects of plasma on polymeric materials have been reviewed by Morent et al. [19] and Pankaj et al. [20]. An increase in surface roughness was observed after plasma treatment in most of the packaging materials like low-density polyethylene [21], polypropylene [22], poly(ethylene terephthalate) [23] and poly(lactic acid) [24]. Depending on the gas composition and severity of treatment conditions, the polymer surface is subject to etching effects, whereby the polymer is continuously degraded [25]. 
The aim of this work is to determine the effects of DBD plasma on surface and bulk properties of antimicrobial zein film and characterize the effect of DBD plasma treatment in the release kinetics of thymol.

\section{MATERIAL AND METHODS}

\subsection{Cast Zein Films with Thymol}

Corn zein films were prepared as described by Mastromatteo et al. [11] with slight modifications. Five grams of zein (Sigma-Aldrich, Ireland) were dissolved into $26 \mathrm{~mL}$ of ethanol at $50^{\circ} \mathrm{C}$. Three grams of glycerol (Sigma-Aldrich, Ireland) were added to the solution and stirred using a hotplate magnetic stirrer for $10 \mathrm{~min}$. Then the solution was cooled to room temperature and $10 \%$ and $20 \%$ of thymol (weight of thymol/weight of dry polymer) (Sigma-Aldrich, Ireland) was added with final stirring for about $10 \mathrm{~min}$. As blank, zein solutions without active agent were also prepared. The film-forming solutions were poured on Petri dishes (diameter $15 \mathrm{~cm}$ ) and dried at ambient conditions under laminar flow hood, until the solvent was completely evaporated and peeled off after $48 \mathrm{~h}$. In this way, zein films with an average thickness of $385 \pm$ $8 \mu \mathrm{m}$ were obtained.

\subsection{Dielectric Barrier Discharge Plasma Treatment}

The schematic of the experimental setup is presented in Figure 1. Briefly, the DBD plasma source consists of two circular aluminium plate electrodes (outer diameter $=158 \mathrm{~mm}$ ) over perspex dielectric layers (10 $\mathrm{mm}$ thickness). When the potential across the gap reaches the breakdown voltage the dielectric barrier acts as stabilizing material for forming a large number of micro-discharges. The applied voltage to the electrode is obtained from a step-up 
transformer (Phenix Technologies, Inc., USA) using a variac. The input of $230 \mathrm{~V}, 50 \mathrm{~Hz}$ was given to the primary winding of high voltage step-up transformer (Phenix Technologies, Inc., USA) from the main supply. To achieve a stable discharge, a 2-mm-thick polypropylene sheet was also used, above which the cast zein film was placed. The distance between electrodes was 22 $\mathrm{mm}$. The atmospheric air condition at the time of treatment was $50 \%$ relative humidity $(\mathrm{RH})$ and $22^{\circ} \mathrm{C}$, as measured using a humidity-temperature probe connected to a data logger (Testo 176 T2, Testo Ltd., UK). Samples were treated at $70 \mathrm{kV}$ for 5 minutes.

In order to identify the excited and reactive species generated by the plasma source, a computer-controlled Stellarnet EPP 2000C-25 spectrometer was employed for optical emission spectroscopy (OES). The emission from the discharge was coupled to the spectrometer using an optical fiber having a numerical aperture of 0.22 . Spectra were obtained at a resolution of 1.5 $\mathrm{nm}$, over the range of 200 to $850 \mathrm{~nm}$. The integration time was $5000 \mathrm{~ms}$ and 8 samples were averaged for the collection of spectra. Identification of spectral characteristics was carried out using NIST atomic spectra database and Gaydon and Pearse [26].

Figure 1 Scheme of the experimental setup for DBD plasma system.

\subsection{Thymol Release}

Thymol release was measured by the method described by Del Nobile et al. [5], with slight modifications. The prepared active films were put into a glass beaker with $250 \mathrm{~mL}$ of distilled water (volume/surface ratio $4.5 \mathrm{~mL} \mathrm{~cm}^{-2}$ ) and shaken at $25^{\circ} \mathrm{C}$ and $150 \mathrm{rpm}$ in an orbital shaker for $180 \mathrm{hr}$. The thymol release kinetics were evaluated by monitoring thymol concentration in the surrounding solution using HPLC (Waters e2695 Separation Module and Waters 2998 
Photodiode Array Detector, Waters Corporation, Ireland), until equilibrium value was achieved. The chromatographic column used was a C18 reverse phase column, $250 \times 4 \mathrm{~mm}$, particle size 5 $\mu \mathrm{m}$. A linear gradient elution with acetonitrile-0.05M orthophosphoric acid was used [27]. Typical gradient used is given in Table 1. The flow rate was $1 \mathrm{~mL} \mathrm{~min}{ }^{-1}$ with injection volume of $5 \mu \mathrm{l}$ and the elution was detected at a wavelength of $277 \mathrm{~nm}$. The calibration curve was constructed for peak area against thymol concentration of standard solutions from 10 to 500 ppm.

Table 1 Gradient elution for determination of thymol.

\subsection{Atomic Force Microscopy (AFM)}

Atomic force microscopy measurements were carried out to observe the surface characteristics of the control and plasma-treated samples. The AFM used was MFP-3D BIO 1126 (Asylum Research, Santa Barbara, CA, USA) operated in intermittent contact (tapping) mode. The images were collected at a fixed scan rate of $0.5 \mathrm{~Hz}$. The sampling rate was 512 lines. Data were processed using MF3D software (version 111111+1219).

\subsection{Thermogravimetric Analysis (TGA)}

Thermogravimetric analysis was performed with a Mettler Toledo thermal analyser, model TGA/SDTA 851e (Schwarzenbach, Switzerland). Approximately $5 \mathrm{mg}$ samples were heated at

$10^{\circ} \mathrm{C} \mathrm{min}^{-1}$ from $30^{\circ} \mathrm{C}$ to $700^{\circ} \mathrm{C}$ under nitrogen atmosphere (flow rate $50 \mathrm{~mL} \mathrm{~min}{ }^{-1}$ ). Initial degradation temperature $\left(T_{5}\right)$ was determined as the temperature at which $5 \%$ mass loss was observed.

\subsection{Differential Scanning Calorimetry (DSC)}


Differential scanning calorimetry analysis was performed with a TA Instruments DSC Q2000 (New Castle, DE, USA) under a dry nitrogen gas flow rate of $50 \mathrm{~mL} \mathrm{~min}^{-1}$. Approximately $5 \mathrm{mg}$ samples were weighed in aluminium pans $(40 \mu \mathrm{L})$ and subjected to two heating-cooling cycles from $-30^{\circ} \mathrm{C}$ to $200^{\circ} \mathrm{C}$ at $10^{\circ} \mathrm{C} \mathrm{min}^{-1}$. Glass transition temperatures $\left(T_{\mathrm{g}}\right)$ were determined during the first heating cycle to evaluate the changes that occurred after plasma treatment.

\subsection{Statistical Analysis}

Analysis of variance was done for all analyses and treatments and significance of difference was assessed using Tukey's comparison tests at significance levels of $p \leq 0.05$. Analysis was carried out in SPSS statistical package (SPSS Inc., Chicago, IL, USA). The mathematical model for thymol release kinetics was performed in Matlab 2012a (MathWorks, USA).

\section{RESULTS AND DISCUSSION}

\subsection{Emission Characteristics of the Discharge}

A typical emission spectrum of the discharge is presented in Figure 2. The most intense peaks in the spectra correspond to the emissions in the near UV region by the excited species of nitrogen, namely nitrogen second positive system $\mathrm{N}_{2}(\mathrm{C}-\mathrm{B})$ and first negative system $\mathrm{N}_{2}^{+}(\mathrm{B}-\mathrm{X})$ [26]. The minor peak around $300 \mathrm{~nm}$ was identified as resulting from $\mathrm{OH}$ excitation. Peaks associated with optical transitions of the $\mathrm{O}$ atom could be observed at low intensities: 725.4 from $O \quad\left(5 s^{3} S \rightarrow 3 p^{3} P\right), \quad 533.0 \quad n m$ from $O \quad\left(5 d^{5} D-3 p^{5} P\right)$, and 777.4 from $O$ $\left(2 s^{2} 2 p^{3} 3 p^{5} P \rightarrow 2 s^{2} 2 p^{3} 3 s^{5} S\right)$. It may be noted that air plasma chemistry is highly complex with participation from over 75 species in almost 500 reactions [28]. This complexity imposes a limitation on the number of species that can be identified; especially the very short time scale 
species in the plasma discharge remain unidentified to this point. Besides those observed through spectroscopy, the dielectric barrier discharge set-up employed was also found to generate significant amounts of ozone [29]. To conclude, the discharge was a potential source of reactive oxygen (ROS) and reactive nitrogen species (RNS).

Figure 2 Representative emission spectrum of the discharge in air.

\subsection{Surface Characteristics}

The surface topographies of control and plasma-treated antimicrobial zein films by atomic force microscopy (AFM) are shown in Figure 3. The roughness parameters for the control and plasmatreated zein film surface are presented in Table 2. It is clear from these results that the DBD plasma treatment leads to increased surface roughness of zein films. The surface topography of untreated antimicrobial zein films is very smooth with root mean square roughness $\left(R_{r m s}\right)$ of only $26 \mathrm{~nm}$, while after DBD plasma treatment at $70 \mathrm{kV}$ for 5 minutes the $R_{\mathrm{rms}}$ of treated films is in the order of $100 \mathrm{~nm}$. The increase in surface roughness after DBD plasma treatment was attributed to the etching effect of DBD plasma. The plasma treatment can lead to chemical etching by breaking bonds, chain scission and chemical degradation of the treated polymer or it can result in physical etching by physically removing low molecular fragments. While chemical etching is promoted by radicals in plasma discharges, physical etching occurs under strong bombardment by energetic particles such as electrons and ions [25,30-32]. The etching effect of plasma is already being harnessed for surface functionalization and cleaning purposes [20], but this study also suggests that the etching effect of plasma also plays an important role in controlling the release kinetics of active compounds from an active packaging material. 
Figure 3 AFM images of the surface of (a) untreated and (b) plasma-treated antimicrobial zein (10\%) film, and (c) plasma-treated antimicrobial zein (20\%).

Table 2 Roughness parameters for untreated and plasma-treated antimicrobial zein films (RRMS: root mean square roughness, RPeak: Highest peak, RGroove: lowest groove).

\subsection{Thermal Properties}

The main indicators of thermal and structural changes are presented in Table 3. In general terms, TGA curves for films showed more than one degradation step. Large changes in the initial degradation temperature $\left(T_{5}\right)$ were observed after plasma treatment for blank film. A strong thermal stabilization of the zein film without antimicrobial agent was achieved after plasma treatment, which is consistent with the observations recorded for neat poly(lactic acid) films [24]. However, for the samples containing thymol, slight changes were observed after plasma treatment, suggesting that the thermal stabilization in these films could be predominantly due to thymol.

On the other hand, plasticized films with thymol showed three degradation steps. The first event was observed at temperatures around $80^{\circ} \mathrm{C}$ and it was related to the loss of ethanol remaining from the casting process. The second stage at temperatures between 200 and $300^{\circ} \mathrm{C}$ could be related to the loss of glycerol and thymol from the material. Finally, the third degradation process, at temperatures above $300^{\circ} \mathrm{C}$, was associated to the protein thermal degradation. 
Glass transition temperature $\left(\mathrm{T}_{\mathrm{g}}\right)$ of untreated films decreased as thymol concentration increased in the blends, as it was expected, since the organic nature of thymol makes it highly compatible with the zein protein and also acts as natural plasticizer in the blends, promoting chain mobility. Blank zein films showed a slight increase in the $T_{g}$ after plasma treatment, which can be also correlated to the increase in $T_{5}$, suggesting some degree of crosslinking at surface level, limiting the chain motion in the rubbery state. A similar increase in $\mathrm{T}_{\mathrm{g}}$ was also observed for the treated antimicrobial films, although it remained below the control zein film in all plasma-treated antimicrobial films. The DSC thermograms also suggested that plasticizer and protein remained a homogeneous material throughout the cooling and heating cycle due to the absence of any phase separation (separated glass transition temperature or melting and crystallization peaks) between plasticizer and film.

Table 3 Initial degradation temperature $\left(T_{5}\right.$, mass loss $\left.=5 \%\right)$ and glass transition temperature $\left(T_{\mathrm{g}}\right)$ for treated and untreated zein films.

\subsection{Release Kinetics of Thymol}

Methodologies for determining the diffusion of additives from the packaging films have been widely discussed in literature [33-36]. In the present study, the antimicrobial compound (thymol) was entrapped into the polymer matrix of zein film. When the film comes in contact with aqueous solution, firstly the water molecules penetrate into the matrix leading to its swelling and making the meshes of the polymeric network wider, allowing the active compound to diffuse through the matrix into the outer solution until a thermodynamic equilibrium between outer solution and polymer is reached. Therefore, the release of thymol from zein 
films depends upon the following phenomena: (1) water diffusion; (2) macromolecular matrix relaxation kinetics; (3) diffusion of the active compound through the swollen polymeric network [36]. Fick's second law of diffusion describes species concentration change as a function of time and position. For unidirectional diffusion, it can be written as Equation 1 [37].

$$
\frac{\delta C_{a}}{\delta x}=D \frac{\partial^{2} C_{a}}{\partial x^{2}}
$$

where $C_{a}$ is the concentration of the diffusing substance; $D$ is diffusivity; $x$ is the coordinate dimension in the direction of transport; and $\mathrm{t}$ is time.

Since the aim of this work was to assess the change in the thymol release kinetics due to DBD plasma treatment, a simple approach, such as reported by Mastromatteo et al. [11], has been used, which assumes that both water diffusion and macromolecular matrix relaxation are much faster than the active compound diffusion through the swollen network, with the negligible change in film size due to swelling. Based on that, Fick's second law intended for a plane sheet with constant boundary condition and uniform initial concentration can be reported as Equation 2.

$$
M(t)=M_{e q}\left[1-\frac{8}{\pi^{2}} \sum_{n=0}^{\infty} \frac{1}{(2 n+1)^{2}} \cdot \exp \left\{\frac{-D \cdot(2 n+1)^{2} \cdot \pi^{2} \cdot t}{h^{2}}\right\}\right]
$$

where $M(t)$ is the amount of thymol released (ppm) at time $t(h r), M_{e q}$ is the amount of thymol released at equilibrium conditions (ppm), D is the thymol diffusion coefficient $\left(\mathrm{cm}^{2} \mathrm{~s}^{-1}\right)$ through the swollen polymeric matrix and $\mathrm{h}$ is the film thickness $(\mathrm{cm})$. 
A significant increase $(p<0.05)$ in the thymol diffusion coefficient after DBD plasma treatment was observed for both thymol concentration levels. The parameters after fitting experimental values to Equation 2 are presented in Table 4. It should be noted at this point that although different release rates after DBD plasma treatment were observed, the equilibrium thymol concentration in the solution remained at the same level of $160 \mathrm{ppm}$ for antimicrobial zein film containing $10 \%$ thymol and $341 \mathrm{ppm}$ for film containing $20 \%$ thymol. It is also evident from the data shown in Figure 4 that the proposed model satisfactorily described the experimental data and, in this specific case, thymol release kinetics could be described through Fick's second law. The increase in the diffusion rate of thymol after DBD plasma treatment can be correlated with the etching effect leading to the increase in surface roughness, which in turn reduced the effective zein thickness and exposed thymol for an accelerated release from the zein film.

Table 4 Parameters obtained by fitting Equation 2 to experimental data. Values are represented as Mean \pm Standard deviation. Means, which are not followed by a common superscript letter, are significantly different $(p \leq 0.05)$.

Figure 4 Release kinetics of thymol from zein films after plasma treatment. $(\bullet)$

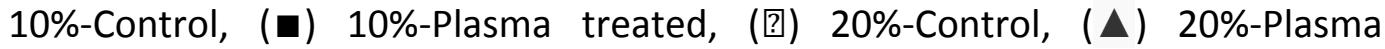
treated. The curves are the fitting experimental data to Equation 2.

\section{CONCLUSION}

This study showed the effect of DBD plasma treatment on zein films containing thymol as an active ingredient. The significant increase $(p<0.05)$ in the film roughness showed the etching 
effect of the DBD plasma, which could also be correlated with the significant increase $(p<0.05)$

in the thymol diffusion rate in the food simulant. No significant changes $(p>0.05)$ in the thermal properties of antimicrobial zein films were observed after plasma treatment, although increased thermal stability was seen for blank zein films. Control of kinetic release parameters by plasma treatment could be a useful practice in the food industry to easily tailor certain food requirements and extend shelf life under controlled conditions. It also forms the impetus for more studies to assess the microbiological efficacy of thymol after DBD plasma treatment.

\section{REFERENCES}

1. European Bioplastics. www.european-bioplastics.org.

2. Siracusa, V., P. Rocculi, S. Romani, and M.D. Rosa, Biodegradable polymers for food packaging: $a$ review. Trends in Food Science \& Technology. 19(12), 634 (2008)

3. Shukla, R. and M. Cheryan, Zein: the industrial protein from corn. Industrial Crops and Products. 13(3), 171 (2001)

4. Shi, K., J.L. Kokini, and Q. Huang, Engineering Zein Films with Controlled Surface Morphology and Hydrophilicity. Journal of Agricultural and Food Chemistry. 57(6), 2186 (2009)

5. Del Nobile, M.A., A. Conte, A.L. Incoronato, and O. Panza, Antimicrobial efficacy and release kinetics of thymol from zein films. Journal of Food Engineering. 89(1), 57 (2008)

6. Appendini, P. and J.H. Hotchkiss, Review of antimicrobial food packaging. Innovative Food Science and Emerging Technologies. 3(2), 113 (2002)

7. Kenawy, E.-R., S.D. Worley, and R. Broughton, The Chemistry and Applications of Antimicrobial Polymers: A State-of-the-Art Review. Biomacromolecules. 8(5), 1359 (2007)

8. Suppakul, P., J. Miltz, K. Sonneveld, and S.W. Bigger, Active Packaging Technologies with an Emphasis on Antimicrobial Packaging and its Applications. J Food Sci. 68(2), 408 (2003)

9. Burt, S., Essential oils: their antibacterial properties and potential applications in foods-a review. Int J Food Microbiol. 94(3), 223 (2004)

10. Stefanakis, M.K., E. Touloupakis, E. Anastasopoulos, D. Ghanotakis, H.E. Katerinopoulos, and P. Makridis, Antibacterial activity of essential oils from plants of the genus Origanum. Food Control. 34(2), 539 (2013)

11. Mastromatteo, M., G. Barbuzzi, A. Conte, and M.A. Del Nobile, Controlled release of thymol from zein based film. Innovative Food Science \& Emerging Technologies. 10(2), 222 (2009)

12. Marino, M., C. Bersani, and G. Comi, Antimicrobial activity of the essential oils of Thymus vulgaris L. measured using a bioimpedometric method. Journal of Food Protection ${ }^{\circledR}$. 62(9), 1017 (1999)

13. Kokkini, S., R. Karousou, A. Dardioti, N. Krigas, and T. Lanaras, Autumn essential oils of Greek oregano. Phytochemistry. 44(5), 883 (1997)

14. Dorman, H.J.D. and S.G. Deans, Antimicrobial agents from plants: antibacterial activity of plant volatile oils. J Appl Microbiol. 88(2), 308 (2000) 
15. Niemira, B.A., Cold Plasma Decontamination of Foods. Annual Review of Food Science and Technology. 3(1), 125 (2012)

16. Misra, N., B. Tiwari, K.S.M.S. Raghavarao, and P. Cullen, Nonthermal Plasma Inactivation of Food-Borne Pathogens. Food Engineering Reviews. 1 (2011)

17. Tendero, C., C. Tixier, P. Tristant, J. Desmaison, and P. Leprince, Atmospheric pressure plasmas: A review. Spectrochimica Acta Part B: Atomic Spectroscopy. 61(1), 2 (2006)

18. Liu, C., N. Cui, N.M.D. Brown, and B.J. Meenan, Effects of DBD plasma operating parameters on the polymer surface modification. Surface and Coatings Technology. 185(2-3), 311 (2004)

19. Morent, R., N. De Geyter, T. Desmet, P. Dubruel, and C. Leys, Plasma Surface Modification of Biodegradable Polymers: A Review. Plasma Processes and Polymers. 8(3), 171 (2011)

20. Pankaj, S.K., C. Bueno-Ferrer, N.N. Misra, V. Milosavljević, C.P. O'Donnell, P. Bourke, K.M. Keener, and P.J. Cullen, Applications of cold plasma technology in food packaging. Trends in Food Science \& Technology. 35, 5 (2013)

21. Ataeefard, M., S. Moradian, M. Mirabedini, M. Ebrahimi, and S. Asiaban, Investigating the effect of power/time in the wettability of $\mathrm{Ar}$ and $\mathrm{O}_{2}$ gas plasma-treated low-density polyethylene. Progress in Organic Coatings. 64(4), 482 (2009)

22. Leroux, F., C. Campagne, A. Perwuelz, and L. Gengembre, Polypropylene film chemical and physical modifications by dielectric barrier discharge plasma treatment at atmospheric pressure. Journal of Colloid and Interface Science. 328(2), 412 (2008)

23. Almazan-Almazan, M.C., J.I. Paredes, M. Perez-Mendoza, M. Domingo-Garcia, F.J. Lopez-Garzon, A. Martinez-Alonso, and J.M. Tascon, Effects of oxygen and carbon dioxide plasmas on the surface of poly(ethylene terephthalate). J Colloid Interface Sci. 287(1), 57 (2005)

24. Pankaj, S.K., C. Bueno-Ferrer, N.N. Misra, L. O’Neill, A. Jiménez, P. Bourke, and P.J. Cullen, Characterization of polylactic acid films for food packaging as affected by dielectric barrier discharge atmospheric plasma. Innovative Food Science \& Emerging Technologies. (In press,accepted), (2013)

25. Mirabedini, S., H. Arabi, A. Salem, and S. Asiaban, Effect of low-pressure $\mathrm{O}_{2}$ and Ar plasma treatments on the wettability and morphology of biaxial-oriented polypropylene (BOPP) film. Progress in Organic Coatings. 60(2), 105 (2007)

26. Gaydon, A. and R. Pearse, The identification of molecular spectra. The identification of Molecular Spectra1976, London: Chapman and Hall.

27. Martel, A.-C. and S. Zeggane, Determination of acaricides in honey by high-performance liquid chromatography with photodiode array detection. Journal of Chromatography A. 954(1-2), 173 (2002)

28. Gordillo-Vázquez, F.J., Air plasma kinetics under the influence of sprites. Journal of Physics D: Applied Physics. 41(23), 234016 (2008)

29. Misra, N.N., D. Ziuzina, P.J. Cullen, and K.M. Keener, Characterization of a novel atmospheric air cold plasma system for treatment of packaged biomaterials. Transactions of the ASABE. 56(3), 1011 (2013)

30. Yang, L., J. Chen, Y. Guo, and Z. Zhang, Surface modification of a biomedical polyethylene terephthalate (PET) by air plasma. Applied Surface Science. 255(8), 4446 (2009)

31. Akishev, Y., M. Grushin, N. Dyatko, I. Kochetov, A. Napartovich, N. Trushkin, T. Minh Duc, and S. Descours, Studies on cold plasma-polymer surface interaction by example of PP-and PET-films. Journal of Physics D: Applied Physics. 41(23), 235203 (2008)

32. Kwon, O.-J., S.-W. Myung, C.-S. Lee, and H.-S. Choi, Comparison of the surface characteristics of polypropylene films treated by Ar and mixed gas (Ar/O2) atmospheric pressure plasma. Journal of Colloid and Interface Science. 295(2), 409 (2006) 
33. Han, J.H. and J.D. Floros, Simulating diffusion model and determining diffusivity of potassium sorbate through plastics to develop antimicrobial packaging films. Journal of Food Processing and Preservation. 22(2), 107 (1998)

34. Gnanasekharan, V., J.D. Floros, and J.R. Glacin, Migration and sorption phenomena in packaged foods. Critical Reviews in Food Science and Nutrition. 37(6), 519 (1997)

35. Arvanitoyannis, I., M. Kalichevsky, J.M.V. Blanshard, and E. Psomiadou, Study of diffusion and permeation of gases in undrawn and uniaxially drawn films made from potato and rice starch conditioned at different relative humidities. Carbohydrate Polymers. 24(1), 1 (1994)

36. Buonocore, G.G., M.A. Del Nobile, A. Panizza, S. Bove, G. Battaglia, and L. Nicolais, Modeling the Lysozyme Release Kinetics from Antimicrobial Films Intended for Food Packaging Applications. Journal of Food Science. 68(4), 1365 (2003)

37. Crank, J., The mathematics of diffusion, 2nd ed. Diffusion in a plane sheet, Oxford university press. (1975) 


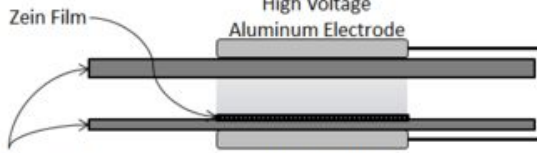

Ground Electrode

\section{Dielectric Barriers}




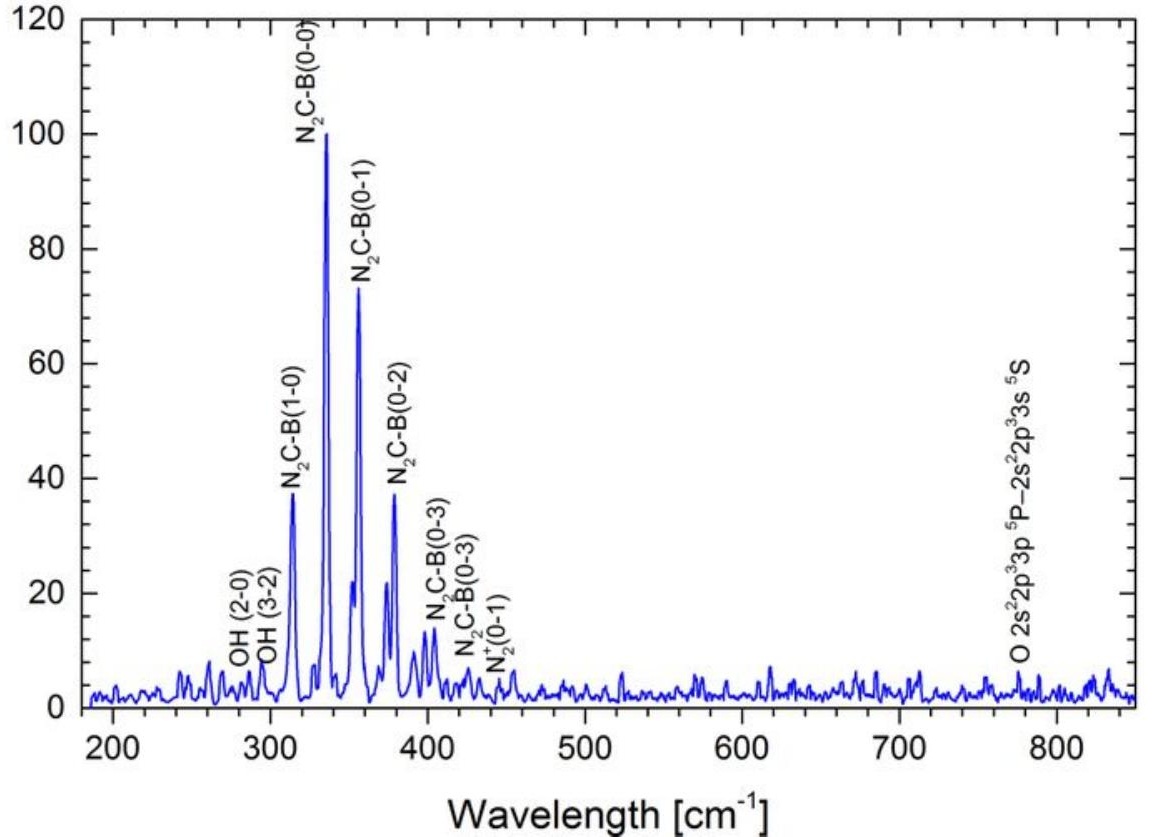


(a)

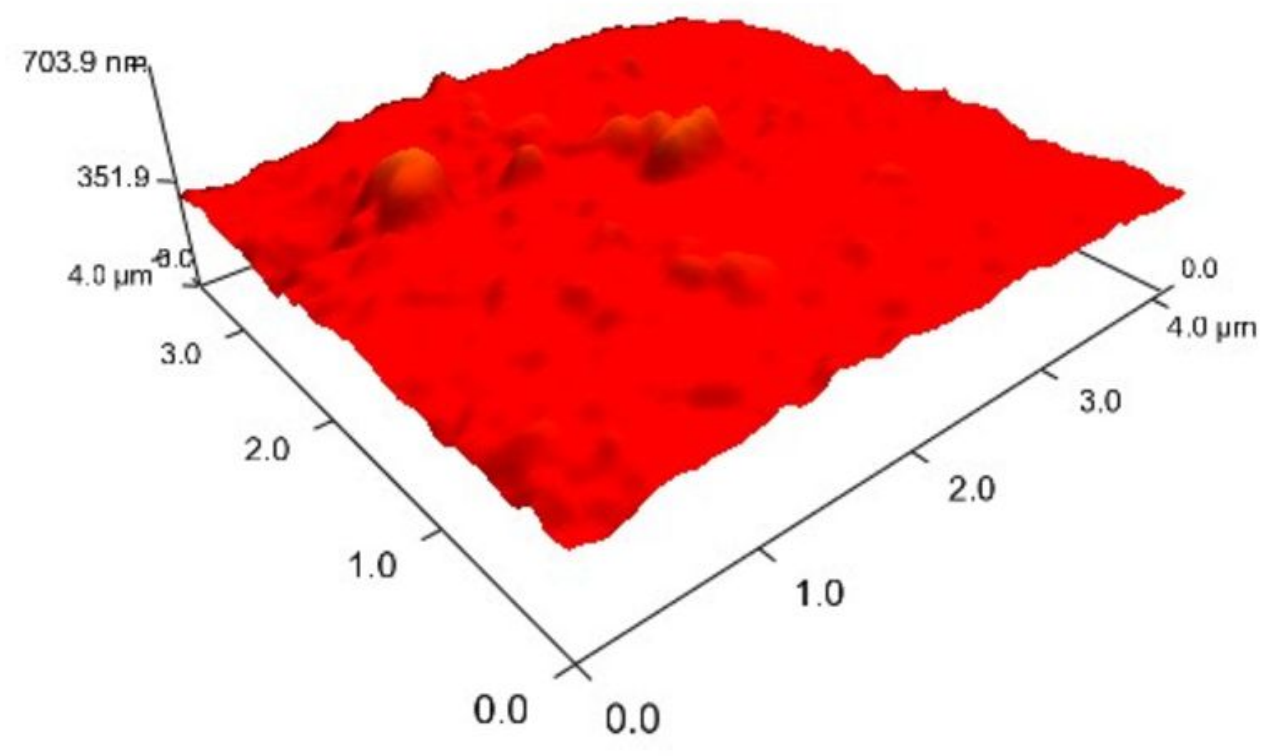

$703.9 \mathrm{~nm}$

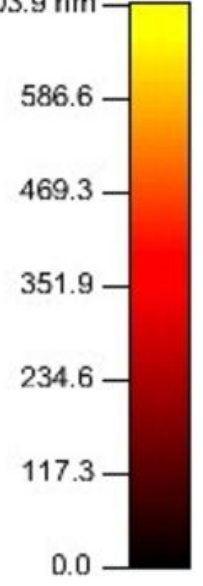


(b)

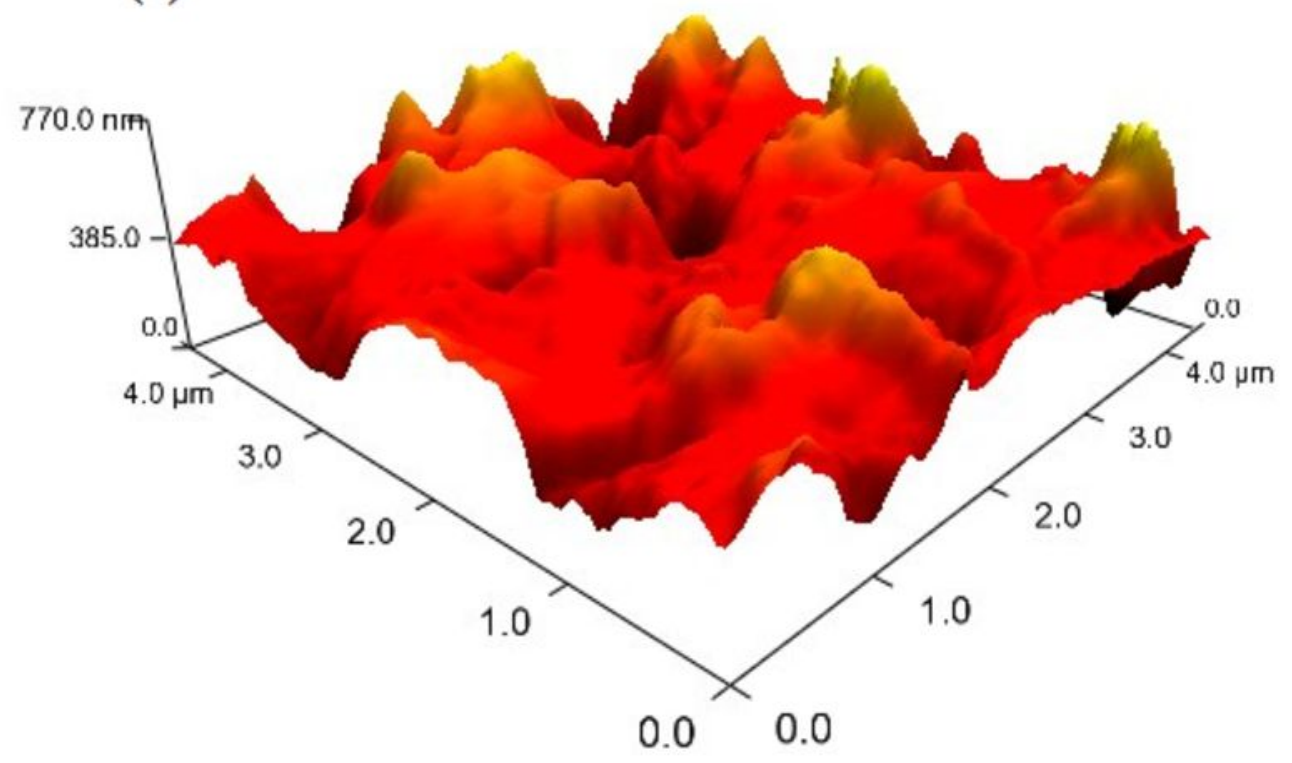

$770.0 \mathrm{~nm}$

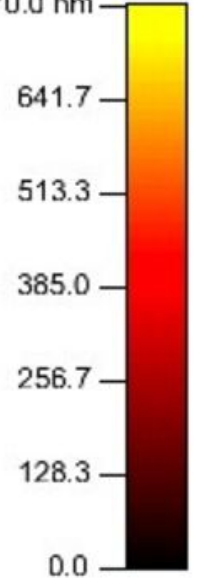


(c)

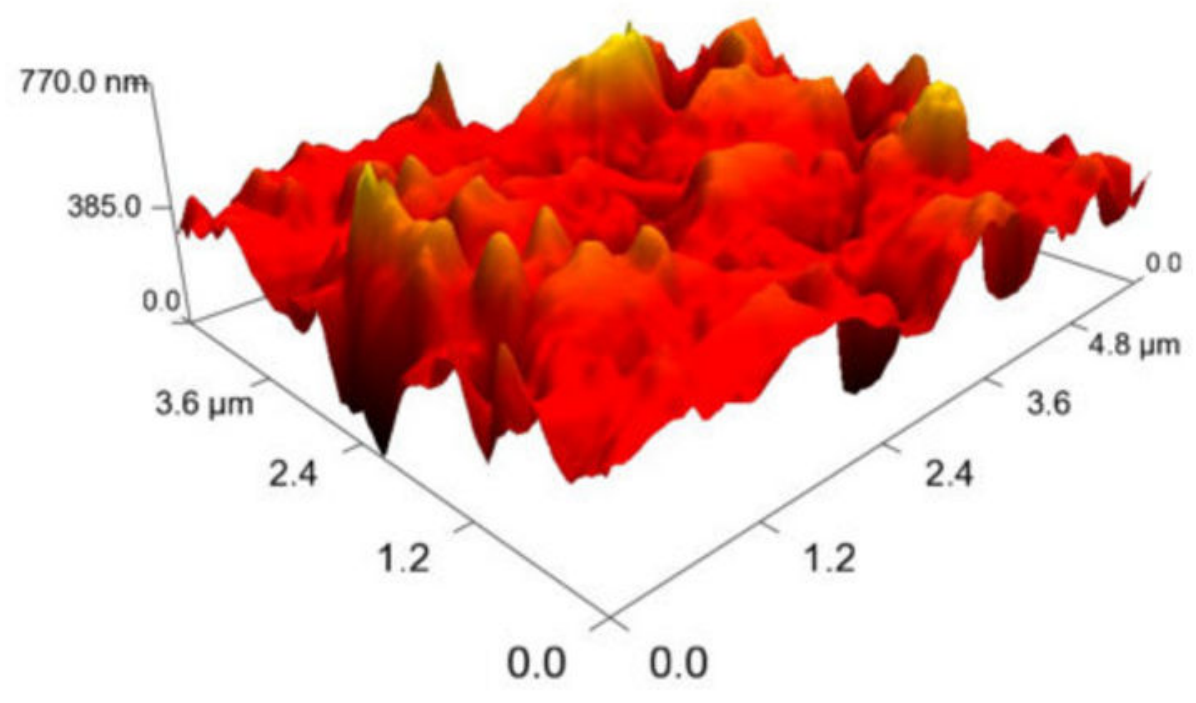

$770.0 \mathrm{~nm}$

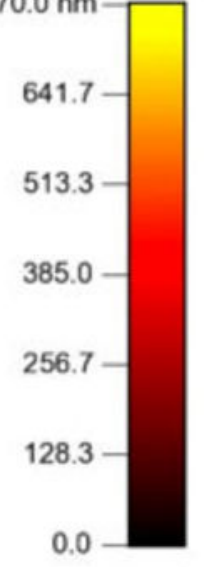




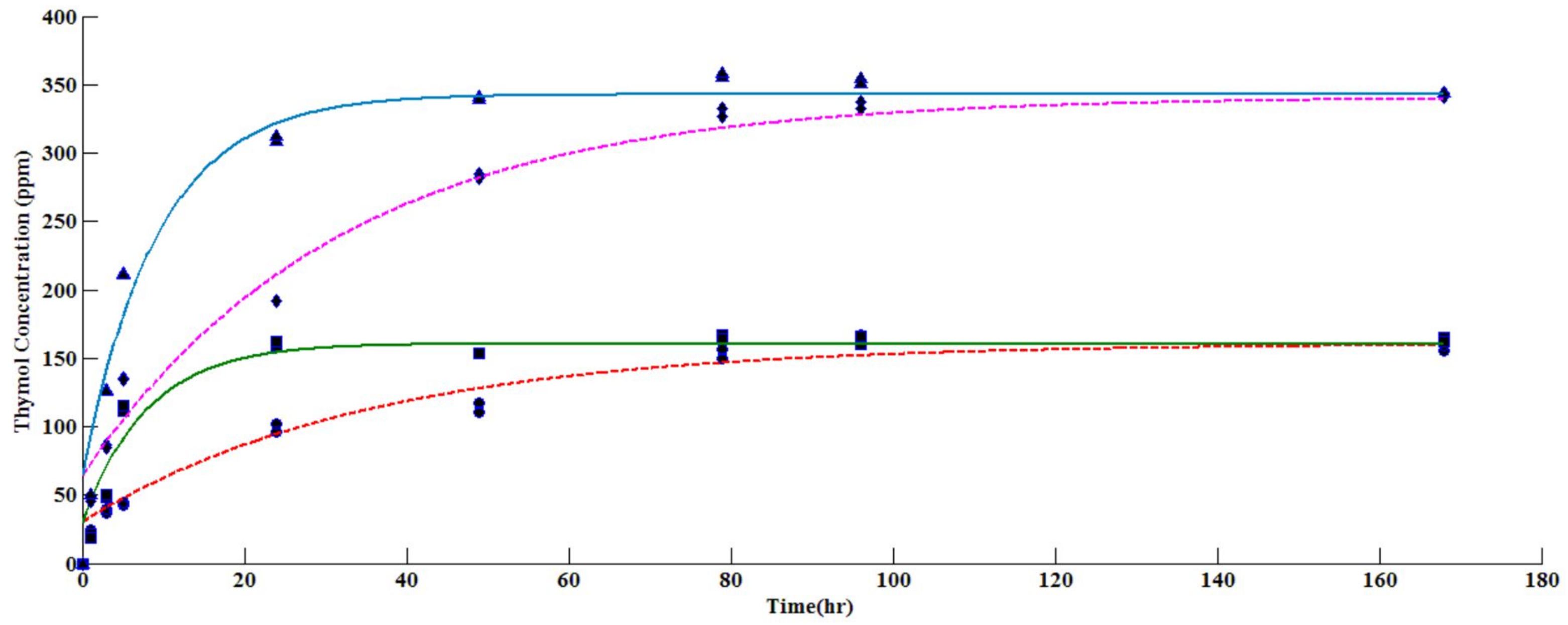




\begin{tabular}{|l|l|l|}
\hline Time (min) & Acetonitrile & 0.05 M orthophosphoric acid \\
\hline 0 & 40 & 60 \\
\hline 7 & 46 & 54 \\
\hline 8 & 60 & 40 \\
\hline 11 & 60 & 40 \\
\hline 20 & 40 & 60 \\
\hline
\end{tabular}

Table 1: Gradient elution for determination of thymol 


\begin{tabular}{|l|l|l|l|}
\hline Characteristics & Untreated & Plasma-treated & Plasma-treated \\
& & $(10 \%)$ & antimicrobial zein (20\%) \\
\hline $\mathrm{R}_{\mathrm{RMS}}(\mathrm{nm})$ & $26.0 \pm 18.9$ & $118.1 \pm 88.9$ & $99.9 \pm 74.7$ \\
\hline $\mathrm{R}_{\text {Peak }}(\mathrm{nm})$ & $143.4 \mathrm{~nm}$ & $519.9 \mathrm{~nm}$ & 337.9 \\
\hline $\mathrm{R}_{\mathrm{GROOV}}(\mathrm{nm})$ & -100.1 & -466.9 & -398.0 \\
\hline Skew & 0.88 & -0.109 & -0.527 \\
\hline Kurtosis & 2.86 & 1.23 & 1.3 \\
\hline
\end{tabular}

Table 2: Roughness parameters for untreated and plasma treated antimicrobial zein films

( $R_{R M S}$ : root mean square roughness, $R_{\text {Peak: }}$ Highest peak, $R_{\text {Groove: lowest groove) }}$ 


\begin{tabular}{|c|c|c|}
\hline Sample & $\mathrm{T}_{5}\left({ }^{\circ} \mathrm{C}\right)$ & $\mathrm{T}_{\mathrm{g}}\left({ }^{\circ} \mathrm{C}\right)$ \\
\hline Control-0\% & 88.1 & 57.3 \\
\hline Control-10\% & 146.5 & 53.3 \\
\hline Control-20\% & 146.1 & 47.9 \\
\hline Plasma treated-0\% & 157.9 & 59.4 \\
\hline Plasma treated-10\% & 147.1 & 53.5 \\
\hline Plasma treated-20\% & 142.1 & 50.9 \\
\hline
\end{tabular}

Table3. Initial degradation temperature $\left(T_{5}\right.$, mass loss $\left.=5 \%\right)$ and glass transition temperature $\left(T_{g}\right)$ for treated and untreated zein films. 


\begin{tabular}{|l|l|l|}
\hline Zein films & D & $M_{\text {eq }}$ \\
\hline $10 \%$-Control & $4.2 \times 10^{-6 a}$ & $160.6 \pm 1.7^{\mathrm{a}}$ \\
\hline $10 \%$-Plasma treated & $1.9 \times 10^{-5 \mathrm{~b}}$ & $160.7 \pm 0.1^{\mathrm{a}}$ \\
\hline $20 \%$-Control & $4.7 \times 10^{-6 \mathrm{a}}$ & $341.1 \pm 3.4^{\mathrm{b}}$ \\
\hline $20 \%$-Plasma treated & $1.6 \times 10^{-5 \mathrm{c}}$ & $342.8 \pm 0.1^{\mathrm{b}}$ \\
\hline
\end{tabular}

Table 4: Parameters obtained by fitting Eq (2) to experimental data. Values represented as

Mean \pm Standard deviation. Means, which are not followed by a common superscript letter, are significantly different $(p \leq 0.05)$. 